\title{
The Degree of Kindergarten Teachers' Practice, in Gaza Governorates, of the Skills of Enhancing Creative Thinking and the Ways to Develop Them
}

\author{
Fayez K. Shaladan \\ Department of Fundamentals of Education, Faculty of Education, Islamic University of Gaza, Gaza Strip, Palestine
}

\section{Email address:}

fshaladan@iugaza.edu.ps

\section{To cite this article:}

Fayez K. Shaladan. The Degree of Kindergarten Teachers' Practice, in Gaza Governorates, of the Skills of Enhancing Creative Thinking and the Ways to Develop Them. Education Journal. Vol. 5, No. 2, 2016, pp. 12-26. doi: 10.11648/j.edu.20160502.11

Received: February 9, 2016; Accepted: March 25, 2016; Published: April 27, 2016

\begin{abstract}
This study aims to determine the degree of kindergarten teachers' practice, in Gaza governorates, of the skills of enhancing creative thinking and the ways to develop them. To achieve this goal, the researcher used the descriptive analytical approach. A questionnaire that was designed, consisted of (42) items distributed on four fields: Skills of discovering the creative ability for children, skills of generating creative ideas for children, skills of solving problem creatively, and skills of developing creative outcome for children. The researcher also used meeting to answer the third question. Study sample included (125) of kindergarten teachers', in Gaza governorates, from the study population which are (410) teachers in the study year of 2013/2014. The researcher used the following statistical methods (SPSS program, mean, percentage and T. test).
\end{abstract}

Keywords: Kindergartens, Teachers, Skills, Enhancing Creative Thinking

\section{Introduction}

Preschool stage is considered the most important stage for the child experience in the beginning of his life, and its impact extends to adulthood. He recognizes the outside world at the beginning of this stage, forming all sides of his personality and gradually drifts apart from his parents to be ready for school where he finds other people who take care of him and he trusts them.

Modern education scientists call for the necessity of the child care in this stage through considering the kindergarten stage an essential phase in education progression because they believe one's personality is forming in these years, as well as all various behavior patterns and habits. Therefore, it is the stage that physical and emotional characteristics and most of the child abilities, aptitudes, interests and inclinations are developed. Moreover, its the growth of most of the child needs, emotional trends, social relations and verbal linguistic sides. That's why the counseling service should be available because it is essential for the child. The child should have the choice to select his activities, games and movements to face world of childhood courageously, open minded, and healthy physically and psychologically to grow up as a happy child and strong man in the future. So, the child should be surrounded by proper educational atmosphere in nurseries and kindergartens (Bishi 0.2008: 3).

This mission is represented by the role of the teacher who is considered one of the effective factors in child adaptation and acceptance of the kindergarten as the first body deals without his family. It plays an important role to help him to develop his talents. The unqualified teacher may shock the child and frustrate him because she neglects the characteristics of growth in this stage. The teacher has an effective impact on the emotional growth, psychological health and the inclinations of the child in general. Education experts are unanimous on the benefits of joining kindergartens, and this is mainly depends on his personality and teacher efficiency. Therefore, all the teachers in the kindergartens should be educationally and professionally qualified. (Spodek, 1972)

This is what aggrandizes the role of kindergarten teacher as surrogate mother for the child, preparing him for the next educational stages. She is responsible for organizing, planning the experiences and bearing the responsibility of bringing up the children, caring of his growth and fulfilling the desired goals in the educational process which includes developing knowledge, trends, values, abilities and habits of each child until he reaches the highest possible point he can. (Hamoud 0.2010: 3).

She also seeks to develop their talents and sharpen their creativity. Although there skills should be learnt because the 
future success depends on, the importance of these skills dwarfs in comparison with the importance of children understanding the nature of learning process and their role in this process. Hence, kindergarten stage (pre-elementary school) represents the years in which the children recognize that learning is fun, they are learners and have a wide range of talents. Outstanding kindergartens guide children to the route of discovery and success (Hoerr, 2009, 700).

Since modern education enhances creative thinking; it confirms that enhancing starts in the first phase of child upbringing because it is considered one of the advanced human activities. It has become a significant problem of scientific research in large number of countries since the 1950 s, because scientific research can't be achieved without the development of human creative abilities. Furthermore, progress and development of humanity depend on the available creative abilities that always enable it to achieve extra creativity and contributions. Through these contributions it can confront all the challenges that worsening day after another. Therefore, many experts and researchers called that future schools are designed not only for education but also for thinking, and the purpose of education must be teaching the children how to think and how to learn. No doubt that this enhances creativity. (Almsharfi, D.t).

A lot of studies confirmed that education built on creative skills kindergarten teacher provide better results than traditional education, and makes teachers more effective and more creative. To raise a creative learner, you need to prepare the teacher to have the basic factors of the effective teacher who has the experience to teach his students the creative thinking. That's what we miss in preparation and rehabilitation of kindergarten teachers programs (Sharif, 2012: 261).

Some studies confirmed the importance of kindergarten stage in enhancing creative thinking through meaningful activities that the teacher gives to children such as (Othman, 2000) study. The study of (Albishi, 2008) referred to the importance of educational rehabilitation of kindergarten teachers to enable them to deal properly with children and the most significant challenges that face kindergartens which relate to teachers preparation. The study of (C. Edwards, K. Springate, 1995) focused on encouraging the creative thinking in kindergarten classrooms while Hanora (2000) concentrated on the importance of creative thinking for the child.

The researcher finds through his observation of kindergarten teachers work, in Gaza governorates, that there is a need to identify the degree of kindergarten teachers' practice to the skills of enhancing creative thinking, in Gaza governorates, because this stage is considered one of the fertile phases for studying and discovering the creators.

\subsection{The Study Findings Show That}

1. The degree of kindergarten teachers' practice to the skills of enhancing creative thinking reached (\% 82.42).

2. There are no statistical significant differences between the averages of the study sample estimates for the degree of kindergarten teachers' practice, in Gaza governorates, to the skills of enhancing creative thinking due to the variable of educational qualifications and the variable of specialization except the fourth field "skills of developing creative outcome for children" in the advantage of the literary specialization.

3. Suggesting a group of methods to enhance the degree of kindergarten teachers' practice to the skills of enhancing creative thinking, in Gaza governorates.

\subsection{The Recommendations from the Study Are as Following Shows}

- Uniting all the bodies of supervision on the kindergartens under the supervision of the ministry of education in order to observe and provide them with what they need.

- Selecting the well-qualified teachers scientifically and educationally and in accordance with standards that meet the ability of creative thinking enhancement for the children.

- Paying much attention from the child-teacher preparation colleges for the skills of enhancing creative thinking for the teachers.

- The administrations of the kindergartens should supply all the requirements that enhance creative thinking skills for the teachers such as scientific laboratories, computers and other tools.

\subsection{The Problems of the Study}

The world witnesses today tremendous progress in all areas of life, because of existence of elite of innovators and thinkers who exceed the limits of conventional thinking and shine with their thoughts and creative works. To keep these innovative models, definitely it should be given much care for children in the earliest stages which represent the stage of human formation now and in the future. It is teachers' responsibility in kindergartens which requires special skills and capacities that allow them to discover the creative abilities for the children, and to develop creative thinking for them. A lot of studies confirmed that education built on creative skills for kindergarten teacher provides better results than conventional education, and makes teachers more effective and more creative. To raise a creative learner, you need to prepare a teacher to have the basic factors of the effective teacher who can give experience teaching to his students to think creatively. That's what we miss in preparation and rehabilitation of kindergarten teachers programs (Sharif, 2012: 261). This research is made to identify the degree of kindergarten teachers' practice, in Gaza governorates, to the skills of enhancing creative thinking for children.

In the light of the above mentioned, research problems can be formulated in the following questions:

1. What is the degree of kindergarten teachers' practice, in Gaza governorates, to the skills of enhancing creative thinking from the teachers' point of view?

2. Are there statistical significant differences at the level $(\alpha \leq 0.05)$ between the averages of the sample members estimates for the degree of their practice of the creative thinking skills due to the variable of (scientific 
qualification, specialization)?

3. What are the ways of enhancing the degree of kindergarten teachers' practice to the skills of developing creative thinking?

\section{Research Objectives}

The current study seeks to achieve the following objectives:

1. To demonstrate the degree of kindergarten teachers' practice, in Gaza governorates, to the skills of enhancing creative thinking from the teachers' point of view.

2. To determine the degree of the existence of statistical significant differences for the degree of kindergarten teachers' practice to the creative thinking skills due to the variable of (scientific qualification, specialization).

3. To suggest ways of enhancing the degree of kindergarten teachers' practice for the skills of developing creative thinking.

\subsection{Research Hypotheses}

1. There are no statistical significant differences at the level $(\alpha \leq 0.05)$ between the averages of the sample members estimates for the degree of kindergarten teachers' practice, in Gaza governorates, to the skills of developing creative thinking due to the variable of scientific qualification (diploma, bachelor).

2. There are no statistical significant differences at the level $(\alpha \leq 0.05)$ between the averages of the sample members estimates for the degree of kindergarten teachers' practice, in Gaza governorates, to the skills of developing creative thinking due to the variable of specialization (scientific, literary).

\subsection{Study Significance}

The significance of the study emerges from the following:

1. It is considered an attempt to identify the degree of kindergarten teachers' practice to the skills of enhancing creative thinking.

2. The important role of kindergarten teacher in enhancing creative thinking for kindergarten children.

3. It opens new horizons to the researchers in the early childhood to study carefully the necessity of developing children abilities.

4. the study is expected to benefit:

- Kindergarten teachers

- The Ministry of Education, to determine the appropriate criteria when choosing kindergarten teachers.

- Institutions of kindergarten teacher preparation such as universities, colleges and institutes.

5. Scarcity of such studies in Palestinian society.

\subsection{Delimitations of the Study}

Objective limit: the study is limited on determination the degree of kindergarten teachers' practice, in Gaza governorates, to the skills of enhancing creative thinking from their points of view through a questionnaire consists of
(42) items distributed on four fields.

Human limit: kindergarten teachers.

Institutional limit: the study is limited on kindergartens

Place limit: the study is applied on Gaza governorates, Palestine.

Time limit: the study is applied in the second semester 2013 - 2014.

Study Terms: The study used the following terms:

Kindergarten teacher: she is the teacher who works at a kindergarten with children from the age of 3, trains and educates them (Khalidi, 2008).

Skill: is the ability to accomplish a certain task on specific way, in extreme accuracy and speed in implementation (Khikany, 2014)

Creative thinking: "An individual's ability to free thinking, which enables him/her to detect problems and mysterious attitudes and reformulate the elements of experience in new patterns by providing the largest possible number of alternatives to reformulate this experience in a various ways and appropriate for the situation that faces the individual so that these new patterns resulting are characterized by modernity for the individual himself and the community in which he lives, and this ability can be trained and developed "(Mansi, 1991: 235).

It is "a type of problem-solving behavior which doesn't differ from other types of thinking but only in the kind of preparation that the individual receives" (Abu Hatab and Sadeq, 1994: 627).

The researcher identifies the degree of kindergarten teachers' practice to the skills of enhancing creative thinking procedurally:

The group of activities and procedures that kindergarten teachers practiced, in Gaza governorates, for the enhancement of creative thinking of kindergarten children, which was measured by a questionnaire prepared by the researcher for this purpose.

\subsection{Introduction}

Since the beginning of the twentieth century, the studies interested in talented are increased. Many books and articles were published interested in their qualities, characteristics of growth, caring of them and also to study the necessary resources to develop their abilities and talents. This is maybe one of the requirements of overall cultural renaissance that modern societies seek to achieve to take advantage of their human resources. That's why many centers and institutions concerned with gifted children were establishment.

Human is one of the most important element for creative production needs, his abilities and skills that are directly influenced by what he receives in childhood. Hence, paying attention to childhood contains paying attention to the present and the future as well. The first five years stage of human life is the most important. Modern society knows and appreciates the importance of childhood. Therefore, he cares about it rather than any other stage because of the importance of the experience at the first years of life in shaping the child future growth. And the chance of achieving human development is highly depends on what the society provides and cares of the child. This confirms that the success of the countries 
culturally, scientifically, and economically is affected by the degree of education programs effectiveness including early childhood stage. (Guinness. 2001: 118).

It seems that the contemporary conflict in the twentieth century among developed countries (brain power conflict) to get scientific antecedence to occupy leading position.

It's a fact that creative thinking is set up since early childhood, each child is a creative project; and must be seen like this. The emergence and basics of creative thinking of the child are presented by the characteristics that distinguish this stage, such as his interest in the exchange of things, how to deal with and identify them. And the interest in exploring, experimenting, and identifying the components or elements of things beside the imaginative power which the child is characterized by, it appears in playing delusional activities, and the large number of questions to satisfy his mental hunger and need to research and investigate (Almshrifi. 2005: 110).

\subsection{The Emergence of Kindergartens}

In the beginning, kindergartens emerged as a social necessity rather than learning and teaching because of the change of the social conditions surround the family, and the mother became qualified to work outside home. In addition, the increasing number of the family members forced it to seek help from other institutions to play similar role in the upbringing the children. So the idea of creating child-care institutions such as nurseries and kindergartens emerged as a result of studies and painstaking efforts of a large number of scientists and philosophers such as John Comenius and JeanJacques Rousseau.

Child pre-school educational institutions in Palestine still occupy a place outside of the known educational system. The Five-Year Plan of the Palestinian Ministry of Education pointed to the need for the development of public education, the education system and non-formal pre-school education (Ministry of Education and Higher Education, 2004).

Gaza strip has been affected by natural evolution in child care centers and kindergartens. That was in the early 1940s when Arif Arif (1942) established the first kindergarten in Gaza City. Then followed by other schools to establish kindergartens, after that, the idea was spread but it was limited. The last ten years witnessed establishing dozens of kindergartens annually, and the number of kindergartens in Gaza Strip reached (51) for the academic year (1982/1981) included about (4792) children, then the number rose to (78) kindergarten for the academic year (1989/1990) included about (7137) children (Mansi 0.1991: 147).

Kindergartens still in constant evolution until the number reached (150) licensed kindergartens in the year (1996) and then in the end of the year 2000/2001 it reached (235) licensed kindergarten, and about (100) to (120) unlicensed kindergarten (Baroud 2002: 55), Then reached so far (473) licensed kindergarten and more than 320 kindergarten unlicensed (and the Palestinian Ministry of Education and the Education 0.2014).

\subsection{Kindergarten Teachers}

Many definitions of the concept of kindergarten teachers were mentioned, and the researcher states only the following:
(Abdel Raouf) defined it: they are educational figures were selected very carefully through a set of standards for physical, mental, social, moral and emotional characteristics which fit the profession of child-upbringing and they receive preparation and training in high colleges to take over the educational work in the education of pre-school institutions responsibilities (Abdel Raouf. 2008: 63).

It is also defined as: the female who is raising children up in kindergarten inside and outside of the activity room through the daily co-existence with children and aims through its work to achieve the educational kindergarten goals (Murtada, Abu Nour, 2003: 16).

The researcher defines it as: the educationally qualified female in universities, colleges and institutes, and have enough good skills to deal with pre-school children.

The required skills of kindergarten teachers:

Required skills of kindergarten teachers can be classified according to the following:

1. Basic Skills: they are represented in the knowledge of Arabic skills, as well as other foreign languages skills such as English, in addition to the development of the patriot side, values and Arab culture.

2. Mental skills: they are represented in teachers' possession of the higher-order thinking skills such as the ability of conclusion, analysis, synthesis, evaluation, summarizing, criticism, generalization, judgment and plans developing skills and others.

3. Technological Technical Skills: such as the ability to design games and tools, manufacturing and employing in the educational process, in addition to have the ability to use the internet and computers in teaching and learning process, to get, develop information, use or transfer them.

4. Practical life skills: such as health and personal care, nutrition, health, sexual awareness, in addition to the rationalization of consumption and the skills of preserving the environment.

5. Social skills: It means teachers' possession of social communication skills with children, fellows, and other social bodies.

6. Practical performance skills: It means the possession of activity planning skills, their implementation and evaluation, as well as the skill of the implementation of modern educational methods in kindergarten such as cooperative learning, role-playing, educational representation, problem solving and others (Sasila, 2010: 13_14).

\subsection{Creative Thinking}

The last quarter of the twentieth century has witnessed a remarkable progress of the interest of psychologists and education experts in the field of creativity and innovators, the fact that this area is closely linked to the communities development and prosperity; because any progress requires the existence of innovators with creative abilities who can contribute to social welfare, this is what encouraged the existence of continuous competition between various communities to reach the top.

Mohamed Abdel Razek (1994), quotes from Almcharfi 
(2003) that creative thinking is responsible for the modern civilizations that human reached over the years, ancestors' products in different civilizations have creativity, and production of modern ages has creativity as well, because without the innovators and their thoughts to life would remain primitive until now. In addition, Creativity is accompanied by happiness and develops people's tastes and feelings. Innovators give us a scientific or technical high-level product that transcends our tastes, makes us accept life, and contribute to enrich it by hard work (Almsharfi, 2003: 29).

Creativity can be defined as "a directed and purposeful thinking style, by which one seeks to discover new relationships, new solutions to problems, to invent or discover new approaches and ways, new devices and to produce beautiful art images (Issawi, 1994: 144).

\subsection{Discovery Process of Creative Thinking for Children}

The discovery of the creative thinking is the most important step that contribute to its development for children, which requires monitoring and observing creative behavior that they have, then following a series of procedures and activities that help the teacher to detect creative children to enable her to adopt some of the methods that contribute to develop their creative thinking. Al-Baghdadi indicates (2001: 14-15) that there are four main postulates have to be recognized for the discovery of creativity among children, which are the following:

1. All children, to some extent, are creative by nature.

2. Some children are more creative than others.

3. Some children are more creative in some aspects than others.

4. Creativity would disappear by the teacher who does not realize the performance, underestimate the child or unable to show child creativity.

Children creativity at the age of (3 -7) can be discovered by the following criteria provided by (Oweis, 1993: 29):

Provoking the child to show the largest number of ways by which specific pale can be reached from another particular one; this part measures the child's ability to create number of kinetic behavior methods.

Motivating the child to play fictional roles such as representing an animal, a topic, or to imitate the adult roles, this part of the test measures the child's ability to imagine and act unfamiliar roles.

Motivating the child to show the largest possible number of ways in which used paper cup can be put in the trash. This part of the test measures the child's ability to use unusual ways to do simple task.

Motivating child's imagination to express and imagine many things such as using cup of paper, hypothetically it's not using cup of paper, could be turned into another thing. What are the shapes that the cup may take? This part of the test measures the child's ability to the creativity of using authentic forms of using cup of paper.

\subsection{The Skills of Enhancing Creative Thinking Among Kindergarten Teachers}

Modern societies interested in developing the teacher skills and performance through various training courses, continuous guidance for teachers to improve their performance and to enable them to prepare and raise the children to be creative to serve and enhance their communities. the study of (Al - A'asar, 1999) confirmed the need to include courses about developing the creative skills in the preparation programs of the Kindergarten teachers, in addition to organizing and administrating teachers training programs to develop their skills (quoted from Sharif, 2012: 19), and these are the creative thinking skills that institutions should be taken into account when they prepare kindergarten teachers:

1. Thinking fluency: It means teacher's ability to generate the largest possible number of ideas that meet the demands of the program and to achieve the activity objectives without regard to the level of these ideas in terms of experience, fluency and skill which is represented in words, shapes and objects. Fluency means to produce the largest possible number of ideas about a particular subject in particular unit (Omari, 1423: 85).

2. Flexibility: It means the teacher's ability to change the mental perspective that she uses to see things and different situations, so that she can be free from mental deficiency and move to different levels of ideas without being restricted to a particular category. Flexibility also means to change the teacher's state of mind by changing the situation (Hussein, and Fakhry, 2004: 53).

3. Originality: It means the teacher's generating to unfamiliar ideas and solutions, because the innovator does not repeat the ideas around him, does not resort to traditional solutions, and less degree of idea prevalence is, greater degree of its authenticity is.

4. Creative imagination: it means the kindergarten teacher's ability to imagine and create relationships between objects through various readings, continuous meetings, developing mind perceptions and enrich its knowledge.

5. Problems sensitivity: it means to see the problem clearly, precisely identify it, and identify its( sizes, dimensions, different aspects and probable effects ) with logical presentation and treatment. And to see the facts as they are and to discover the relationships between them (Abrahem, 1993: 93).

The researcher confirms that these skills should be at the top priorities that the kindergarten teachers must master, and should be taken in consideration when they employed, so that they should undergo certain tests measuring their ability to develop children's creativity

\section{Literature Review}

After studying a range of previous Arabic and foreign studies closely related to the subject of this study, presented in chronological order from the newest to the oldest, as follows:

Sharif (2012) study entitled "creative skills of the teacher as an entrance to the professional performance quality in kindergarten, the study aimed to find out the creative skills of the kindergarten teacher and its relationship with the professional performance quality, the researcher used 
observation to achieve the objectives of the research. It has been applied to a number of teachers in (6) kindergartens in of Cairo and Giza city, the study sample included (50) teachers the study findings were as follows:

- There are statistical significant differences at the level (0.01) between the averages of teachers' scores who have less than 5 years of service in acquiring creative skills in comparison with the total degree of the observation card in favor of teachers who have more than 10 years of service.

- There are statistical significant differences at the level $(0.01)$ between the averages of teachers' scores who are specialists and non-specialists in acquiring creative skills for the benefit of specialists teacher.

- There are statistical significant differences at the level (0.01) between the averages of teachers' scores of governmental kindergartens and the means of private kindergarten teachers' scores in acquiring creative skills for the benefit of private kindergarten teachers.

- There is a positive statistical significant correlation (0.01) between the availability of creative skills of teacher and professional performance quality for her in comparison with the total score of observation card as a whole.

- Canaan (2007) study, entitled: A Vision for kindergarten teacher preparation and rehabilitation in accordance with the quality systems requirements, the study aimed to visualize the kindergarten teacher preparation in accordance with the kindergarten quality requirements in open education department at the University of Damascus. Descriptive analytical method was used. The study was applied on a sample of the student at the kindergarten department at the open education at the university, and some of the study findings were:

- Putting a measure to kindergarten teacher preparation, starting with teacher preparation curriculum which should be characterized by clarity, and corresponds with the quality standards as well.

- There are obvious inabilities in some aspects in the process of teacher preparation in this section, the most important is the inadequacy of buildings, lack of teaching aids, language laboratories and activities application centers as well as that the program suffers a lot of defects and inabilities in accordance to the standards of comprehensive quality systems requirements.

Madeni (2005) study, entitled: The most important obstacles that separate kindergarten teacher and her role towards gifted children, the researcher used the descriptive approach, and the study population consisted of all governmental and private kindergarten children in Jeddah, a random sample has been selected of them reached (36) teachers, (18) teachers from the governmental kindergartens, and (18) a teachers from private kindergartens. The researcher adopted the personal interview and used statistical analysis to deal with the study variables, while she used the quantitative analysis for the rest of answers through registering the interview answers on papers prepared for this. And the most important results of study are the following:

- Most teachers believe that the daily burdens which they have prevent them to discover gifted children.
- Some teachers believe that the reason is due to the inadequacy of some kindergarten buildings, also the lack of sufficient appropriate tools and equipment to detect and care for the gifted.

- They lack the knowledge about the characteristics of the gifted and the way to discover and care them.

- The administration doesn't give the teacher enough flexibility to deal with children.

- Kindergarten teachers' qualification is not sufficient, and they lack much of the basic information.

Almashrifi (2003) study, entitled "Effectiveness of the proposed program for developing the competencies of creative thinking teaching among female teacher students at kindergarten college, the study aimed to prepare a program for developing the competencies of creative thinking teaching among teacher students at kindergarten college, the researcher used the experimental method with one group, and it includes a randomly selected sample consisted of (20) students of the third year at the kindergarten college Alexandria University, distributed on (10) classes, two teacher students in each class of the Al-Obour Experimental School Kindergarten and Balqees Experimental School Kindergarten under the management of Wasat for Education in Alexandria. The second section includes a randomly selected sample consisted of (70) children from kindergarten children at the second level of the classes of the two schools where the teacher students work during their practical training, seven children in each class, and the results of the study were as follows:

The effectiveness of the proposed program in developing creative thinking competencies for the teacher students.

The effectiveness of the proposed program in the developing creative thinking for the children of teacher students.

Yassin study (2003), entitled: kindergarten teachers skills evaluation in the holy capital, the study aimed to determine the general basic skills for governmental kindergarten teachers in the holy capital, and the degree of availability to every teacher of the study sample which consisted of (78) teachers at (7) governmental kindergartens. The researcher used a tool consisted of (58) skill, she also used the descriptive analytical method, the results found the following:

Kindergarten teachers in government kindergarten schools enjoy excellent personal competences and high degree.

The degree of these skills do not vary according to specialization or academic qualification, and the level of kindergarten teachers' performance to teaching competencies is weak and they need training and proficiency for all teaching skills.

The degree of availability of basic educational skills for the kindergarten teachers do not vary depending on years of service or the number of courses they have attended

King Sasson Lee (1998) study, entitled: Developing competencies for kindergarten teachers in Korea. The study aimed to identify the kindergarten objectives, activities and programs used, the researcher used descriptive analytical approach, and the researcher developed a questionnaire included hundred questions about kindergarten objectives, the various fields of activities such as mental, kinetic, 
emotional, social and linguistic. The questionnaire was distributed on 200 kindergartens; in addition, the researcher visited the kindergarten personally. The study findings in the field of objectives show that the kindergartens aim, in importance order, to the following:

- Develop the emotional and social area for children.

- Develop the children abilities and concepts to solve their basic problems.

- Develop good listening and habits for children.

- Develop kenotic and Sensory abilities for the children.

Comment on literature review: Through previous presentation, it is possible to say that the relationship between previous studies and the current study are in the following points:

Areas of the agreement:

- Most studies confirmed the importance of the teachers' role in kindergarten institutions in terms of care, preparation and education.

- They revealed a set of skills that must be available in the kindergarten teacher to play her role in promoting the creative side to the children.

- Most of the studies agreed on the importance of preparation and training for the kindergarten teacher.

In terms of the curriculum: The descriptive approach is used as Canaan study (2007), the of Medeni (2005) study, Yassin (2003) study and the study of the Sasson Keng Lee (1998).

In terms of the study population and sample:

All studies relied on study population from kindergarten teachers as Sharif (2012) study, Canaan (2007) study, Medeni (2005) study, Almsharfi (2003) study and the study of Yassin (2003).

In term of the study tool: This study agreed with the study of Canaan (2007) and the study of Yassin (2003).

The differences: The study differs in terms of the curriculum with the study of Sharif (2012) which used observation card and the study of Almsharfi (2003) which used the experimental method.

In terms of the study tool this study differs from the study Medeni (2005) which used personal interview, and study of Sharif (2012) which used observation card.

Aspects to benefit of previous studies: the researcher benefited from these studies in the following:

- Introduction composition.

- Formation more comprehensive idea about the study subject.

- Determination the most appropriate method and approach.

- Determination the variables of the study, and identifying the appropriate statistical methods.

Aspects of Excellence: Things distinguishes the current study from the previous studies are the following:

- The study uses two tools, questionnaire and interview.

- It presents suggestions to develop creative thinking skills for kindergarten teachers in Gaza Governorates.

\section{Methods and Procedures}

It has a detailed description of the procedures the researcher followed in the implementation of the study, including identifying the study method, descripting of the study population, determining the study sample, preparing the study tools (questionnaire and interview) and checking their validity and reliability, stating the study procedures, and statistical methods used in processing results. Here, in the following, is a description of these procedures.

First: the study method:

The researcher used the descriptive analytical method which is "a form of an organized scientific analysis and interpretation to describe a phenomenon or a specific problem, and representing it quantitatively by collecting specific data about the phenomenon or the problem, classifying it, analyzing it and precisely studying it" (Melhem, 2002: 324) The researcher has been pursued it to determine the questionnaire items and its formulation in the form of consequential skills.

Table 1. Demonstrates the study population.

\begin{tabular}{llll}
\hline S. & Area & Teachers number & Percentage \\
\hline 1 & North Governorate & 454 & 20.6 \\
2 & Gaza Governorate & 639 & 29.2 \\
3 & Middle Governorate & 289 & 13.2 \\
4 & Khan Younis Governorate & 427 & 19.4 \\
5 & Rafah Governorate & 386 & 17.6 \\
Total & & 2195 & $100 \%$ \\
\hline
\end{tabular}

Secondly: the original population of the study:

The study population consisted of all kindergarten teachers in Gaza Governorates of the academic year (2013-2014) and their numbers are (2195) teachers, they have been distributed as follows:

Thirdly: The study sources: The study is based on two basic types of data:

(1)Primary data: by researching in the practical side through distributing questionnaires to study some of the study items, determining and collecting the necessary data about the subject of the study. Then filling and analyzing it using SPSS program (Statistical Package for Social Science). The researcher used the appropriate statistical tests in order to reach the valuable interpretations and indicators support the subject of the study.

(2) Secondary data: The researcher did a review of the related books, periodicals and publications about the study subject which related to the determination of the degree of kindergarten teachers in Gaza Governorates of creative thinking skills and the ways to develop them in order to enrich the subject of the study scientifically, in order to identify the basics and appropriate scientific methods in writing scientific studies, as well as having an idea about the latest developments that occurred after the study.

Fourthly: the study sample:

(A)The pilot sample:

The researcher selected a random pilot sample consisted of (20) teachers of kindergarten teachers who have been excluded from the original community in order to verify the validity of the three standards to be implemented on the field sample members in the Palestinian environment, then calculated its validity and reliability by the appropriate statistical methods.

(B) The actual study sample: 
The study sample included at (125) teachers of kindergarten teachers in Gaza for the academic year (20132014), the questionnaire has distributed to the study sample, the following table shows the distribution of the study sample according to its variables:

Table 2. The distribution of respondents according to the variables of study.

\begin{tabular}{llll}
\hline Variable & Variable category & Number & Percentage \\
\hline \multirow{2}{*}{ Qualification } & Diploma & 60 & $52 \%$ \\
Total & Bachelor & 65 & $48 \%$ \\
Specialization & literary & 125 & $100 \%$ \\
Total & scientific & 25 & $20 \%$ \\
\hline
\end{tabular}

Table (2) illustrates the Distribution of study sample according to the study variables.

Fifthly: study tool:

Through reviewing the educational literature, the researcher built the study questionnaire that aimed to identify the degree of kindergarten teachers' practice, in Gaza Governorates, to the skills of enhancing creative thinking and ways to develop them. After the results of the study that had been reached, the researcher used a second tool which was interview to make advantages of different views in providing ways for developing the degree of teachers' practices:

\section{The first tool (questionnaire):}

After reviewing the educational literature, and in the light of the previous studies according to the study problem, and in the light of a sample of specialists opinion poll through personal interviews, the researcher concluded certain dimensions, and built a questionnaire according to the following steps:

Key dimensions have been identified that make up the questionnaire.

Formulating the items that fall under each field.

Preparing the questionnaire in its initial form, which included 44 items distributed to the fields of the questionnaire.

Modifying the questionnaire initially.

Presenting the questionnaire to a group of specialist arbitrators, some of them are members at the faculty at the Islamic University and Al Quds Open University.

After making adjustments recommended by the arbitrators, two items were deleted as well as some were modified and formulated. The number of the items of the questionnaire after the final formulation reached (42) items distributed on four fields, where each item was given a weight listed according to Quintet Likert scale.

- Thus study sample is limited between (42-210) degree.

- Distribution of the questionnaire to all study sample members to collect the necessary data for the study, the questionnaire has been divided into two parts as follows:

The first part contains the general characteristics of the study population and the study sample.

The second part consists of 42 items distributed on four fields as follows:

- Skills of discovering the creative ability for children (11).

- Skills of generating creative ideas for children (11).

- Skills of problem solving creatively (9).

- Skills of developing creative outcome for children (11).

\section{Questionnaire validity:}

Questionnaire validity means: it measures what has been prepared to measure (Assaf, 1995: 429), validity also means " the coverage of the questionnaire to all the elements that must be included in the analysis, and the clarity of its clauses and vocabulary as well, to be understood by all whoever wants to use it (Obidat and et al, 2001: 179), and the researcher codified the items of the questionnaire to ensure the validity of the study tool, and it has been ensured from the validity of the questionnaire items in two ways:

\section{Arbitrators' validity:}

The researcher introduced the questionnaire in its initial image of a group of arbitrators consisted of (7) members of the faculty members at the Islamic University, Al Quds Open University, and the researcher asked the arbitrators to express their views on the appropriateness of the items to measure what they were developed for, the clarity of their formulation, the appropriateness of each item to the field to which it belongs, and to suggest what they deem necessary to modify the formulation of items, to delete or add new ones based on the directives made by the arbitrators, the researcher conducted the amendments agreed to by the majority of the arbitrators, which was modified the formulation of items and deleted two. In light of those views, two items were excluded and some are modified, so the number of the items of the questionnaire becomes (42).

2. The validity of internal consistency:

the validity of internal consistency of the questionnaire were checked by implementing the questionnaire to a pilot sample of (20) teachers from outside the study sample, Pearson correlation co-efficient was calculated between each item of the questionnaire and the total score of the field to which it belongs, as well as Pearson correlation between the scores of each field in the questionnaire and the total score of the questionnaire, using the statistical software (SPSS).

Table (3) demonstrates the correlation coefficient between each item, its field and the significance level.

Table 3. Field of discovering the creative ability for the children.

\begin{tabular}{lll}
\hline Item number & Correlation coefficient & significance level \\
\hline 1 & $.260^{* *}$ & .003 \\
2 & $.260^{*}$ & .021 \\
3 & $.345^{* *}$ & .000 \\
4 & $.410^{* *}$ & .000 \\
5 & $.486^{* *}$ & .000 \\
6 & $.489^{* *}$ & .000 \\
7 & $.496^{* *}$ & .000 \\
8 & $.243^{* *}$ & .006 \\
9 & $.368^{* *}$ & .000 \\
10 & $.405^{* *}$ & .000 \\
11 & $.494^{* *}$ & .000 \\
\hline
\end{tabular}

** $\mathrm{T}$ when tabular degree of freedom (38) and at the level of significance $(0.01)=0.393$

* $\mathrm{T}$ when tabular degree of freedom (38) and at the level of significance $(0.05)=0.304$

The previous table shows the correlation coefficients between each item of the field and the total score of its items, which shows that the correlation coefficients indicated a function at the level of significance (0.01), and correlation coefficients are limited between the range (0.544-0.832), and thus the items of the field are considered valid to what they 
were put to measure.

Table (4) demonstrates correlation coefficient between each item, its field and the significance level.

Table 4. Field: skills of generating creative ideas in children.

\begin{tabular}{lll}
\hline Item number & Correlation coefficient & significance level \\
\hline 1 & $.294^{* *}$ & .001 \\
2 & $.404^{* *}$ & .000 \\
3 & $.521^{* *}$ & .000 \\
4 & $.615^{* *}$ & .000 \\
5 & $.184^{*}$ & .040 \\
6 & $.372^{* *}$ & .000 \\
7 & $.350^{* *}$ & .000 \\
8 & $.524^{* *}$ & .000 \\
9 & $.245^{* *}$ & .006 \\
10 & $.260^{* *}$ & .003 \\
11 & $.283^{* *}$ & .001 \\
\hline
\end{tabular}

** $\mathrm{T}$ when tabular degree of freedom (38) and at the level of significance $(0.01)=0.393$

* T when tabular degree of freedom (38) and at the level of significance $(0.05)=0.304$

Table 5. Field: skills of problem solving creatively.

\begin{tabular}{lll}
\hline Item number & Correlation coefficient & significance level \\
\hline 1 & $.364^{* *}$ & .000 \\
2 & $.450^{* *}$ & .000 \\
3 & $.653^{* *}$ & .000 \\
4 & $.468^{* *}$ & .000 \\
5 & $.626^{* *}$ & .000 \\
6 & $.601^{* *}$ & .000 \\
7 & $.460^{* *}$ & .000 \\
8 & $.691^{* *}$ & .000 \\
9 & $.664^{* *}$ & .000 \\
\hline
\end{tabular}

** $\mathrm{T}$ when tabular degree of freedom (38) and at the level of significance $(0.01)=0.393$

* T when tabular degree of freedom (38) and at the level of significance $(0.05)=0.304$

The previous table shows the correlation coefficients between each item of the field and the total score of its items, which shows that the correlation co-efficient indicated a function at the level of significance (0.01), and correlation coefficients are limited between the range (0.337-0.754), and thus the items of the field are considered valid to what they were put the measure.

Table (5) demonstrates correlation coefficient between each item, its field and the significance level.

The previous table shows the correlation co-efficients between each item of the field and the total score of the its items, which shows that the correlation coefficients indicated a function at the level of significance $(0.01,0.05)$, and correlation coefficients limited between the range $(0.398$ 0.709), and thus the field items of the field are considered valid to what they have been put the measure.

Table (6) demonstrates correlation coefficient between each item, its field and the significance level.

Table 6. Field: skills of developing creative outcome for children.

\begin{tabular}{lll}
\hline Item number & Correlation coefficient & significance level \\
\hline 1 & $.544^{* *}$ & .000 \\
2 & $.319^{* *}$ & .000 \\
3 & $.590^{* *}$ & .000 \\
4 & $.352^{* *}$ & .000 \\
5 & $.512^{* *}$ & .000 \\
6 & $.580^{* *}$ & .000 \\
7 & $.624^{* *}$ & .000 \\
8 & $.637^{* *}$ & .000 \\
9 & $.610^{* *}$ & .000 \\
10 & $.514^{* *}$ & .000 \\
11 & $.509^{* *}$ & .000 \\
\hline
\end{tabular}

** $\mathrm{T}$ when tabular degree of freedom (38) and at the level of significance $(0.01)=0.393$

* T when tabular degree of freedom (38) and at the level of significance $(0.05)=0.304$

The previous table shows the correlation coefficients between each item of the field and the total score of their items, which shows that the correlation co-efficient indicated a function at the level of significance (0.01), and correlation coefficients are limited between the range (0.337-0.754), and thus the items of the field are considered valid to what they were put the measure.

2. The researcher calculates the correlation co-efficient between each field of the questionnaire with the total score, as it illustrated in Table (7).

Table 7. The correlation co-efficient between each field of the questionnaire and the total score of the scale.

\begin{tabular}{|c|c|c|c|c|}
\hline S. & Field & Item number & Correlation coefficient & significance level \\
\hline 1 & Skills of discovering the creative ability for children & 11 & $.726^{* *}$ & .000 \\
\hline 2 & skills of generating creative ideas in children & 11 & $.771^{* *}$ & .000 \\
\hline 3 & skills of problem solving creatively & 9 & $.887^{* *}$ & .000 \\
\hline
\end{tabular}

It is shown in Table No. (7) that all fields of the questionnaire are linked statistically significant with the total score of the questionnaire.

Calculating questionnaire reliability: it has been ascertained through:

Retail midterm method: retail method was used to calculate the reliability of the questionnaire after it was tested on a pilot sample of the study population which consists of (20) teachers, reliability co-efficient was calculated and it was $(0.82)$. These values indicate that the questionnaire is characterized by high reliability.

Cronbach's alpha method: questionnaire reliability was confirmed by Cronbach's alpha method and it equaled (0.903) and it is an excellent co-efficient in such studies.

The second tool: the interview:

The researcher conducted an interview with some specialists in the field of child-rearing to identify ways to enhance the degree of kindergarten teachers practice, in Gaza Governorates, to a creative thinking skills. 


\section{Study Findings and Interpretation}

It includes the presentation of the results of the study, by answering questions of the study and reviewing the most prominent results of the questionnaire, which was reached through items analysis, in order to identify the degree of kindergarten teachers practice, in Gaza Governorates, to skills of developing creative thinking, and discussing the study variables which included (specialization and qualification). Statistical treatment of the data which was collected from a questionnaire was conducted by using statistical packages for Social Studies program (SPSS) to get the presented and analyzed study findings.

The answer to the first question of the study questions:

The first question of the study questions is: "What is the degree of kindergarten teachers' practice, in Gaza Governorates, the skills of creative thinking from the teachers point of view themselves?

To answer this question, the researcher used the frequencies, means and percentages. And the following tables illustrate this:

Table 8. The mean, the relative value and the test value for each field of the questionnaire.

\begin{tabular}{|c|c|c|c|c|c|}
\hline S. & Field & Mean & Standard deviation & The relative value & Rank \\
\hline 1 & Skills of discovering the creative ability for children & 45.50 & 5.118 & 82.72 & 2 \\
\hline 2 & skills of generating creative ideas in children & 45.48 & 4.519 & 82.69 & 3 \\
\hline 3 & skills of problem solving creatively & 37.26 & 5.021 & 82.80 & 1 \\
\hline Total & & 173.10 & 17.416 & 82.42 & \\
\hline
\end{tabular}

It is shown in table (8) that the total score for the degree of kindergarten teachers' practice, in Gaza Governorates, of skills of developing creative thinking was high and with relative weight $(82.42 \%)$, and the researcher attributes it to:

- Most kindergartens institutions administrations pay attention to this aspect due to what they witnessed of competitive situation among them.

- There are specific criteria that most kindergarten institutions focus on when they select teachers, including criteria relate to skills of creativity enhancement.

- The importance of this stage of the child life as his $\backslash$ her character is formed from all social, intellectual and creative aspects.

As can be seen from the above table that the field of skills of problem-solving creatively has got the first rank with relative weight $(82.80 \%)$ which is high and the researcher attributes this to:

- Children kick up a wide range of questions, and the teachers have to answer these questions in a distinguished way.
- The nature of education at this stage depends on such method because it fits with their mental abilities.

- Solving problems creatively is the most important thing that the child learn in this stage.

As can be seen in the above table that the field of skills of developing creative outcome for children got the last rank in relative weight $(81.54 \%)$ which is high and the researcher attributes this to:

- Most of the teachers feel the children on the importance of their creativities and provide them with appropriate moral or material motivations.

- To interpret the results relate to the degree of kindergarten teachers' practice, in Gaza Governorates, of skills developing creative thinking from the teachers point of view themselves, the researcher prepared the following tables that illustrate the four fields of the questionnaire as follows:

The first field: Skills of discovering the creative ability for children.

Table 9. The frequencies, means, standard deviations and the relative value of each item of the first field: skills of discovering the creative ability for the children, as well as their ranks.

\begin{tabular}{|c|c|c|c|c|c|}
\hline S. & Item & Mean & Standard deviation & The relative value & Rank \\
\hline 1 & I ask the children open questions & 4.16 & .90161 & 83.20 & 6 \\
\hline 2 & I encourage the children to ask inside the class & 4.35 & .71002 & 87.00 & 4 \\
\hline 3 & I listen to the children ideas carefully & 4.39 & .7394 & 87.80 & 3 \\
\hline 4 & I create a suitable environment for discovery & 4.03 & 1.05445 & 80.60 & 9 \\
\hline 5 & I give opportunities for free activities & 3.88 & 1.05188 & 077.6 & 10 \\
\hline 6 & I give the children a chance to express themselves & 4.42 & .67518 & 88.40 & 2 \\
\hline 7 & I allow some humor during the activities I present & 4.25 & .89716 & 85.00 & 5 \\
\hline 9 & I presents activities encourage the creative thinking for the children & 4.10 & .79132 & 82.00 & 8 \\
\hline 10 & I identify the strength points for the children to develop & 4.48 & .69096 & 89.60 & 1 \\
\hline 11 & I record behavioral changes in children's cumulative record & 3.26 & 1.27092 & 65.20 & 11 \\
\hline
\end{tabular}

It is shown in the above table that the two top items in this field were:

- item Number (10), which stipulates " I identify the strength points for the children to develop " is ranked the first with relative weight of $(89.60 \%)$ which is very high and the researcher attributes it to:

That dealing with learners at any stage requires recognition of their abilities first, which requires the need to possess this skill.

Identify the strengths and weaknesses points that are one of the fundamentals which the educational process depends on at all stages.

- It is very logical that teachers possess the skill of proficiency among the students to enhance competition with each other.

- Item number (6), which stipulates, "I give the children a 
chance to express themselves" is ranked the second with a relative weight of $(88.40 \%)$ which is very high and the researcher attributes it to:

- It is natural that teachers possess such skill to know the children's ideas, especially that children in this age provoke a lot of ideas and questions.

- it is important to give the child a chance to express his her opinion to show his her mentality abilities.

As it is clear in the above table that the lowest two items in this field were:

Item number (5), which stipulates "I give opportunities for free activities" is ranked penultimate with relative weight of $(77.60 \%)$ which is very high and the researcher attributes it to:

- Most teachers provide some activities that fit children ages and their mental abilities.

- Some teachers consider that large numbers of children in the same classroom do not allow them to practice any activity.

- Free activities are one of the ways and the means that give the child the opportunity to develop his $\backslash$ her mental and linguistic abilities.

Items number (11), which stipulates "I record behavioral changes in children's cumulative record" is ranked the last one with relative weight of $(65.20 \%)$ which is moderate and, the researcher attributes it to:

Kindergarten teachers believe that this is not their tasks according to the large numbers of children in the same classroom.

The teachers only observe the behavioral changes and take steps to guide them to the better.

The second field: skills of generating creative ideas in children

Table 10. The frequencies, means, standard deviations and the relative value of each item of the second field: skills of generating creative ideas in children, as well as their ranks.

\begin{tabular}{|c|c|c|c|c|c|}
\hline S. & Item & Mean & Standard deviation & The relative value & Rank \\
\hline 1 & I use dialogue to generate ideas in children & 4.45 & .66604 & 89.00 & 2 \\
\hline 2 & I accept their ideas no matter how simple and do not underestimate the value & 4.59 & .70820 & 91.80 & 1 \\
\hline 3 & I allow adequate time for children to explore & 4.08 & .91595 & 81.60 & 7 \\
\hline 4 & I focus on the creativity process in children more than the product & 3.91 & .95896 & 78.20 & 10 \\
\hline 5 & I avoid criticism of children's ideas and ways of thinking & 3.47 & 1.10407 & 69.40 & 11 \\
\hline 6 & I always try to activate children imagination & 4.11 & .89996 & 82.20 & 6 \\
\hline 7 & I judge the value of each idea from children until the end & 3.92 & .90853 & 78.40 & 9 \\
\hline 9 & I offer opportunities to learn without the threat & 4.36 & .79855 & 87.20 & 4 \\
\hline 10 & I feel free to accept children mistakes & 4.39 & .80217 & 87.80 & 3 \\
\hline 11 & I follow their ideas without trying to remodel to fit adult ideas & 3.93 & .90468 & 78.60 & 8 \\
\hline
\end{tabular}

It is shown in the above table that the top two items in this field were:

-item No. (2), which stipulates "I accept their ideas no matter how simple and do not underestimate the value" is ranked the first with relative weight of $(91.80 \%)$ which is very high and the researcher attributes it to:

The instructions issued by the administration ask the teachers to necessarily deal with the ideas and fantasies that children may mention and try to develop them.

That failure to deal with these ideas sometimes causes frustration among children, and increases the degree of repression.

-item number (1), which stipulates "I use dialogue to generate ideas in children" is ranked the second with a relative weight of $(89.00 \%)$ which is very high and the researcher attributes it to:

It is natural that dialogue is the appropriate method for children at this age, and any other method may adversely affects them.

Children have a lot of creative ideas and cannot be extracted, only through quiet dialogue.

As it is shown in the above table that the lowest two items in this field were: item number (4), which stipulates "I focus on the creativity process in children more than the product" is ranked penultimate with relative weight of $(78.20 \%)$ which is a high and the researcher attributes that to:

Most teachers directs children towards creativity without regard to what things may produce.

Transferring children creative ideas to tangible and productive things needs tools and laboratories which the institutions lack in Gaza Strip.

Item number (5), which stipulates "I avoid criticism of children's ideas and ways of thinking" is ranked last with a relative weight of $(69.40 \%)$ which is moderate and the researcher attributes that to:

That any criticism of the children ideas will be reflected negatively on the process of creative thinking.

Lack of experience of some teachers who cannot properly deal with children.

The third field: skills of problem solving creatively

Table 11. The frequencies, means, standard deviations and the relative value of each item of the third field: skills of problem solving creatively.

\begin{tabular}{|c|c|c|c|c|c|}
\hline S. & Item & Mean & Standard deviation & The relative value & Rank \\
\hline 1 & I present ambiguous attitudes and puzzling problems to raise children's thinking & 3.72 & 1.10424 & 74.40 & 9 \\
\hline 2 & I define the lesson problem and ask the children & 4.12 & .82891 & 82.40 & 6 \\
\hline 3 & provide children with information to solve the problem & 4.18 & .77651 & 83.60 & 3 \\
\hline 4 & I encourage them to develop alternatives to solve the problem & 4.12 & .80922 & 82.40 & 7 \\
\hline 5 & I value the suggested ideas and choose the acceptable ones & 4.13 & .91002 & 82.60 & 5 \\
\hline 6 & I help children to validate the hypothesis that they expect & 3.86 & .99470 & 77.20 & 8 \\
\hline 7 & I take in consideration the individual differences among them & 4.68 & .66498 & 93.60 & 1 \\
\hline 9 & I allow them to co-operate to find appropriate solutions to the problems & 4.26 & 1.00116 & 85.20 & 2 \\
\hline
\end{tabular}


As it is shown from the above table that the top two items in this field were:

- item number (7), which stipulates " I take in consideration the individual differences among them " is ranked first with relative weight of $(93.60 \%)$ which is very high and the researcher attributes that to:

- It is natural for everyone works in the field of education to have good skills to take into individual account the differences among learners.

- Children are different in their abilities and circumstances; therefore, it is necessary to take into individual account the differences among them.

Item number (9), which stipulates, "I allow them to cooperate to find appropriate solutions to the problems" is ranked the second with a relative weight of $(85.20 \%)$ which is very high and the researcher attributes that to:

- Most teachers seek to enhance creative abilities in children through collective thinking.

- Some teachers find it difficulties in co-operative teamwork in crowded classrooms.

- collective thinking leads to converge ideas and adopt good innovative ideas

As it can be seen from the above table that the lowest two items in this field were:

Item number (6), which stipulates "I help children to validate the hypothesis that they expect" is ranked penultimate with relative weight of $(77.20 \%)$ which is high and the researcher attributes that to:

Most teachers have the ability to guide the children to relate what they are thinking with what is in reality.

Some teachers, lack such skill due to either the lack of experience or the overcrowded classes.

Item number (1), which stipulates "I present ambiguous attitudes and puzzling problems to raise children's thinking" is ranked the last with a relative weight of $(74.40 \%)$ which is high and the researcher attributes that to:

Most teachers believe that children have a lot of creative ideas that cannot extracted only through stimulating them.

Some teachers lack such skill for personal or educational reasons.

The fourth field: skills of developing creative products for children

Table 12. The frequencies, means, standard deviations and the relative value of each item of the forth field: skills developing creative outcome for children.

\begin{tabular}{|c|c|c|c|c|c|}
\hline S. & Item & Mean & Standard deviation & The relative value & Rank \\
\hline 1 & I prevent children from assessing themselves negatively & 3.52 & 1.32942 & 70.40 & 10 \\
\hline 2 & I encourage children to think aloud & 3.37 & 1.22911 & 67.40 & 11 \\
\hline 3 & I use the appropriate reinforcement methods & 4.59 & .62341 & 91.80 & 1 \\
\hline 4 & I guide the children to keep their thoughts & 3.69 & 1.29655 & 73.80 & 9 \\
\hline 5 & I encourage children to apply their ideas & 4.00 & 1.06632 & 80.00 & 7 \\
\hline 6 & I encourage objective competition among children on their creative work & 4.32 & 1.01282 & 86.40 & 4 \\
\hline 7 & I introduce their creative work on different occasions & 4.19 & 1.08283 & 83.80 & 6 \\
\hline 9 & I encourage the spirit of adventure and challenge in children & 4.37 & .81976 & 87.40 & 3 \\
\hline 10 & I enhance the creative behavior of children & 4.55 & .73458 & 91.00 & 2 \\
\hline 11 & I encourage children to self-evaluation & 4.25 & .89187 & 85.00 & 5 \\
\hline
\end{tabular}

As it is shown from the above table that the top two items in this field were:

- item number (3), which stipulates "I use the appropriate reinforcement methods" is ranked the first with relative weight of $(91.80 \%)$ which is very high and the researcher attributes that to:

- Teachers understand types of the appropriate methods for this age, and their ability to interact with the children.

- The seriousness of the methods used with children to develop creative thinking on them.

Item number (10), which stipulates "I encourage children to self-evaluation" is ranked the second with a relative weight of $(91.00 \%)$ which is very high and the researcher attributes that to:

- Teachers' awareness of the importance of the moral and material reinforcement in the development of creative thinking of children.

- The appropriate reinforcement encourages children on creative thinking.

As it can be seen from the above table that the lowest two items in this field were:

Item number (1), which stipulates "I prevent children from assessing themselves negatively" is ranked penultimate with relative weight of $(70.40 \%)$ which is high and the researcher attributes that to:

Most teachers teach very well and promote children's selfconfidence in their tasks.

Children at this age are not able to evaluate themselves, and their assessment by themselves, reflected negatively on them psychologically and scientifically.

Item number (2), which stipulates "I encourage children to think aloud" is ranked the last with a relative weight of $(67.40 \%)$ which is moderate high and the researcher attributes that to:

Overcrowding of classes may not allow the teachers to encourage children to think aloud, as not to affect the tranquility and order.

The other teachers believe that thinking aloud encourages children to compete and take advantage of others and their ideas.

The answer to the second question of the study questions:

Which states "Are there any statistical significant differences at the level of significance $(\alpha \leq 0.05)$ between the averages of study sample estimates to the degree of kindergarten teachers' practice of skills of creative thinking development due to the variable (qualification, specialization)?

To answer this question, the researcher checked the following hypotheses: 
The first hypothesis of the hypotheses of the study:

It states that: There were no statistical significant differences at the level of significance $(0.05 \geq \alpha)$ between the averages of study sample estimates to the degree of kindergarten teachers' practice of the skills of creative thinking development due to the variable of qualification (Diploma, Bachelor).

To validate this hypothesis, the researcher used the "T. test" and the table (13) illustrates this:

Table 13. The means, dimension deviations and T'value for questionnaire due to the variable of qualification (Diploma, Bachelor).

\begin{tabular}{|c|c|c|c|c|c|c|c|c|}
\hline S. & Field & Qualification & Number & Mean & dimension deviations & "T" value & $\begin{array}{l}\text { Significance } \\
\text { value }\end{array}$ & Significance level \\
\hline \multirow{2}{*}{1} & \multirow{4}{*}{$\begin{array}{l}\text { Skills of discovering the } \\
\text { creative ability for children } \\
\text { skills of generating creative } \\
\text { ideas in children }\end{array}$} & Diploma & 60 & 45.56 & 4.58 & \multirow{2}{*}{-.460} & \multirow{2}{*}{.695} & \multirow{2}{*}{ Not significant on 0.01} \\
\hline & & Bachelor & 65 & 45.96 & 4.9777 & & & \\
\hline \multirow{2}{*}{2} & & Diploma & 60 & 45.30 & 4.89873 & \multirow{2}{*}{-.680} & \multirow{2}{*}{.511} & \multirow{2}{*}{ Not significant on 0.01} \\
\hline & & Bachelor & 65 & 45.85 & 4.03254 & & & \\
\hline \multirow[b]{2}{*}{3} & skills of problem solving & Diploma & 60 & 37.46 & 5.01895 & \multirow{2}{*}{-.005} & \multirow{2}{*}{.984} & \multirow[b]{2}{*}{ Not significant on 0.01} \\
\hline & creatively & Bachelor & 65 & 37.46 & 4.60440 & & & \\
\hline 4 & outcome for children & Bachelor & 65 & 44.39 & 6.63044 & 1.144 & .265 & Not significant on 0.01 \\
\hline \multirow{2}{*}{\multicolumn{2}{|c|}{ Total }} & Diploma & 60 & 174.06 & 16.86145 & \multirow{2}{*}{.125} & \multirow{2}{*}{.885} & \multirow{2}{*}{ Not significant on 0.01} \\
\hline & & Bachelor & 65 & 173.68 & 16.06479 & & & \\
\hline
\end{tabular}

The results shown in Table (13) shows that the probable value (Sig.) Corresponding to the "T - test for two independent samples" is greater than the significance level ( $\alpha \leq 0.05$ ) for all fields and the total score, thus it can be concluded that there were no statistical significant differences between the averages of study sample estimates for the degree of kindergarten teachers' practice of the skills of creative thinking development due to the variable qualification (Diploma, Bachelor).

The researcher attributed to:

The kindergarten institutions administrations direct the teachers on the bases of specific curriculum, and appropriate activities within the annual plan without regard to their qualification.

- The expertise that the teachers possess through dealing with children neglected the differences between the
Diploma and Bachelor certificates.

- Improving creative thinking among children doesn't connected with the teachers scientific certificates.

This result is consisted with the results of Yassin study (2003), which indicated no differences according to academic qualification.

The second hypothesis of the hypotheses of the study:

It states that: There were no statistical significant differences at the level of significance $(0.05 \geq \alpha)$ between the averages of study sample estimates to the degree of kindergarten teachers' practice of the skills of creative thinking development due to the variable of specialization (scientific, literary).

To validate this hypothesis, the researcher used the "T. test" and the table (14) illustrates this:

Table 14. The means, dimension deviations and "T"value for questionnaire due to the variable of Specialization.

\begin{tabular}{|c|c|c|c|c|c|c|c|c|}
\hline S. & Field & Specialization & Number & Mean & dimension deviations & "T" value & $\begin{array}{l}\text { Significance } \\
\text { value }\end{array}$ & Significance level \\
\hline \multirow{2}{*}{1} & Skills of discovering the & Literary & 25 & 47.30 & 5.07610 & \multirow{2}{*}{1.746} & \multirow{2}{*}{.062} & \multirow{2}{*}{ Not significant on 0.01} \\
\hline & creative ability for children & Scientific & 100 & 45.40 & 4.63409 & & & \\
\hline \multirow{2}{*}{2} & skills of generating creative & Literary & 25 & 45.00 & 4.52267 & \multirow{2}{*}{.671} & \multirow{2}{*}{.575} & \multirow{2}{*}{ Not significant on 0.01} \\
\hline & ideas in children & Scientific & 100 & 45.70 & 4.50925 & & & \\
\hline \multirow[b]{2}{*}{3} & skills of problem solving & Literary & 25 & 37.69 & 5.34649 & \multirow{2}{*}{.256} & \multirow{2}{*}{.650} & \multirow[b]{2}{*}{ Not significant on 0.01} \\
\hline & creatively & Scientific & 100 & 37.41 & 4.70352 & & & \\
\hline 4 & outcome for children & Scientific & 100 & 45.46 & 5.69929 & -2.470 & .032 & significant on 0.01 \\
\hline \multirow{2}{*}{\multicolumn{2}{|c|}{ Total }} & Lirary & 25 & 172.17 & 20.37077 & \multirow{2}{*}{-.553} & \multirow{2}{*}{.778} & \multirow{2}{*}{ Not significant on 0.01} \\
\hline & & Scientific & 100 & 100 & 174.2800 & & & \\
\hline
\end{tabular}

The results shown in Table (14) shows that the probable value (Sig.) Corresponding to the "T - test for two independent samples" is greater than the significance level ( $\alpha \leq 0.05$ ) for all fields of the total score with the exception of the fourth field, skills of creative product development for children, thus it can be concluded that there are no statistical significant differences between the averages of study sample estimates of kindergarten teachers' practice of the skills of creative thinking development due to the variable of specialization (scientific, literary) with the exception of the fourth field in favor of literary specialization and the researcher attributes it to:

- All teachers exert great effort in dealing with children without consideration of specialization.

- Management recommendations to the teachers do not differentiate them according specialization; but to all teachers without expectation.

- For the fourth field, the teachers with literary specialization sometimes encourage creative activities and ideas morally and materially because they value this matter in children.

This result is consistent with the results of the Yassin study (2003), which indicated no differences depending on the specialization.

The answer to the third question of the study questions:

It states that: "What are the ways of developing the degree 
of kindergarten teachers' practice of the skills of developing creative thinking?

To answer this question, the researcher conducted interviews with some of the specialists in the field of childrearing to identify ways to develop the degree of kindergarten teachers' practice of the skills of developing creative thinking, and suggestions were as follows:

1. Providing physical environment and appropriating social psychology to promote creative thinking among children.

2. Ecruiting qualified teachers with specialized certificates in child-rearing based on the results of tests for this purpose to select the best.

3. Graduating kindergarten teachers should pass appropriate period of training before granting certification to work in the field of childhood.

4. Caring for integrated and comprehensive preparation of the teachers includes creative thinking skills, life skills and other skills.

5. Directing communication between the sources of teachers' preparation and kindergarten institutions, whether it's after graduation or during the practice of the profession.

6. Preparing training courses for teachers to promote the skills of creative thinking they have.

7. Participating teachers in workshops to develop their skills and to identify their problems to treat them.

8. Including courses relates to creative thinking skills in the programs of preparing kindergarten teachers.

9. Discussing the problems that the teachers suffer from in the work, and identifying treatment ways.

\section{Recommendations}

- Unifying the supervision of the kindergarten institutions under the supervision of the Ministry of Education to be able to follow them up and to provide them with what they need.

- The necessity of selecting qualified teacher educationally, scientifically and in accordance to the standards that -corresponds with the ability to develop creative thinking in children.

- Colleges of preparing children teachers should pay attention to develop creative thinking skills among teachers.

- The kindergarten departments administrations must provide everything needed to enhance creative thinking skills among teachers such as computer and scientific laboratories and other equipment.

- Providing appropriate motivations for teachers to play their roles perfectly.

- Preparing educational meetings for teachers to discuss issues and problems that affect the development of creative thinking among children.

- Studying the challenges which faced the children and prevented the promotion of creative thinking.

- Preparing suitable educational environment to improve creative thinking among children.

- Involving local community organizations and parents to help in developing creative thinking among children.

- Contributing the Ministry of Education in providing creative programs for kindergarten.

\section{References}

[1] Abu Hatab, Fuad, sadeq, Amal (1991) research methods and statistical analysis methods in psychological, educational and social sciences, the Anglo-Egyptian, Cairo.

[2] Ibrahim, Najib Iskandar (1993), the school administration and creativity, working paper submitted to the third seminar in a series of seminars creativity, Cairo 0.29 31 October.

[3] $\mathrm{Al}$ asar, Safa (1999) thinking development is a right to every child, childhood and Development magazine, no. zero, the Arab Council for Childhood and Development, November, $\mathrm{p}$. 77110 .

[4] Baroud, Mahmoud (2002), administrative and technical problems for kindergartens of the Islamic Society and ways of treating them from the viewpoint of those who made it, Master Thesis, Islamic university.

[5] Al-Baghdadi, Mohammad Reda (2001), creative activities for children, Dar Alfiqr Alarabi, Cairo.

[6] Bishi, Ghzayel Hussein (2008) guidelines needs of kindergarten teachers in the educational area of Tabuk, Master Thesis, Faculty of Education, Mutah University, Jordan.

[7] Guinness, Eric (2001) How do we employ brain research in Education, Educational Book House for Publishing and Distribution, Dhahran, Saudi Arabia.

[8] Hussein, Thaer, and Fakhri Abdel-Nasser (2004) thinking skills guide, Johaina for publication and distribution, Jordan.

[9] Al-Hamoud, Hana Kassem (2010) The role of kindergarten teacher in building economic values among kindergarten children between the ages of (5-6 years), Master Thesis, Faculty of Education, University of Damascus, Syria.

[10] Al-Khalidi, Mary (2008) kindergarten teacher between reality and ambition, studies and research, university student library, Mecca.

[11] Alkhikany, Hind Mohammed (2014) concept of skill, Faculty of Fine Arts, University of Babylon, Iraq.

[12] Al-Sharif, Mr. Abdelkader (2012) creative skills as an input parameter for the quality of professional performance in kindergarten, childhood and education magazine Egypt, p. 9, C 1, the four year, pp. 257334.

[13] Sasila, Rania (2010) proposed a strategy for the development of kindergarten teacher preparation system in the light of contemporary educational trends, Damascus University.

[14] Abdul Rauf, Tariq (2008) kindergarten, a good institution for printing and publishing, Damascus parameter.

[15] Omari, Saeed Awad (1423) The impact of incentives on Managing Creativity in governmental organizations, Journal of King Khalid Military College Riyadh, No. 71, pp. 87113.

[16] Aweys, Afaf (1993), the creator of the child, "a pilot study using creative drama," Zahra Library, Cairo.

[17] Issawi, Abdul Rahman Mohammed (1991) Personality Psychology, the psychology of creativity, culture magazine psychological, GS 7, $2 \mathrm{mg}$, Center for Psychological Studies physical, Tripoli, Lebanon.

[18] Murtada, Salwa Abu Nour, Hasnaa (2003), the entrance to kindergartens, Damascus University Press. 
[19] Medini, Manal Ibrahim (2005), the most important barriers between kindergarten teacher and her role towards gifted children, Journal of the Gulf children, Center of disabled Study and Research, pp. 426_443.

[20] Almcharfi, Inshirah Ibrahim (D.t) models of the methods of discovering capabilities of creative thinking among kindergarten children.

[21] Almcharfi, Inshirah Ibrahim (2005), teaching creative thinking for kindergarten children, the Egyptian house, Cairo.

[22] Almcharfi, Inshirah Ibrahim (2003) Effectiveness of the proposed program for developing the competencies of creative thinking teaching among students at the Faculty of kindergarten teachers, $\mathrm{PhD}$ thesis, University of Alexandria.

[23] Melhem, Sami (2002) research methods in education and psychology, Dar Al Maseera for publication and distribution, Amman.

[24] Mansi, Kamel (1991) kindergartens in the Gaza Strip, Samed Institution, GS 8, Oman, Carmel Publishing House, pp. 175 147 .
[25] Muncie, Mahmoud Abdel-Halim (1991) Educational Psychology for teachers, Dar Al Marefa Al Jameyya, Alexandria.

[26] Yassin, Nawal (2003) evaluation of the skills of kindergarten teachers in the holy capital. Almekdsh. cilh Umm Al-Qura University in the capital, Volume XV, Issue 1, p S.151-112.

[27] Hoerr, Thomas, (2009) "Preschool", in Kerr, Barbara (ed.), Encyclopedia of Giftedness, Creativity and Talent, vol. 2 (Thousand Oaks, California: SAGE Publications Inc.), pp. 700-701.

[28] Kanqs son Gvulel (1998) For creative Dincein structure fork mdery attend children in korea PAD, university, New York.

[29] Spodek, B. (1972). Teaching in the early years. New York, Englewood Chiffs. Prentice-Hall. 